\title{
Intoxicação por Mascagnia rigida (Malpighiaceae) em ovinos e caprinos ${ }^{1}$
}

\author{
Jackson S. de Vasconcelos ${ }^{2}$, Franklin Riet-Correa ${ }^{3^{*}}$, Antônio Flávio M. \\ Dantas $^{3}$, Rosane M.T. Medeiros ${ }^{3}$, Glauco José N. Galiza ${ }^{4}$, Diego M. Oliveira ${ }^{4}$ \\ e André F.A. Pessoa ${ }^{4}$
}

\begin{abstract}
Vasconcelos J.S., Riet-Correa F., Dantas A.F.M., Medeiros R.M.T., Galiza G.J.N., Oliveira D.M. \& Pessoa A.F.A. 2008. [Poisoning by Mascagnia rigida (Malpighiaceae) in sheep and goats.] Intoxicação por Mascagnia rigida (Malpighiaceae) em ovinos e caprinos. Pesquisa Veterinária Brasileira 28(10):521-526. Hospital Veterinário, CSTR, Universidade Federal de Campina Grande, Patos, PB 58700-000, Brazil. E-mail. franklin.riet@pq.cnpq.br

Mascagnia rigida is the most important toxic plant for cattle in the Northeastern region of Brazil, causing sudden death during exercise. The objectives of this research were to report three outbreaks of poisoning by $M$. rigida in sheep and one in goats in the semiarid of the state of Paraíba, to reproduce experimentally the disease, and to determine if the active principle of the plant is eliminated through the milk. The outbreaks occurred at beginning of the raining season, when the plant sprouts ahead other forages, or after the end of the raining season, when $M$. rigida stayed green and other forages had dried. In the experimental reproduction of the poisoning doses of 10 and $20 \mathrm{~g}$ of $M$. rigida per $\mathrm{kg}$ body weight from two different regions were lethal to 3 goats and 3 sheep. One goat that ingested $20 \mathrm{~g} / \mathrm{kg}$ and a sheep that ingested $10 \mathrm{~g} / \mathrm{kg}$ recovered. Two sheep and two goats that ingested $5 \mathrm{~g} / \mathrm{kg}$ had mild clinical signs and recovered. Clinical signs of experimental and spontaneous cases were ingurgitation of the jugular veins, reluctance to move, sternal recumbence, incoordination, respiratory distress, depression, instability, and muscular tremors. Death occurred after a clinical manifestation period of about $4 \mathrm{~min}$ to $27 \mathrm{~h} 40 \mathrm{~min}$. The main lesions were pulmonary edema and vacuolization and necrosis of epithelial cells in some renal tubules. To test if the active principle of $M$. rigida causes sudden deaths in newborn lambs and kids, $2 \mathrm{~g} / \mathrm{kg}$ of the plant were given daily to two goats and five sheep in the 15 days previous to parturition. One sheep aborted two lambs, 5 days before parturition. The four lambs of the other four sheep ingested the colostrum without problems. The kid from one goat ingested the colostrum and died suddenly 5 minutes after. The kid from the other goat died immediately after parturition before ingestion of colostrum. These results suggest that the active principle of $M$. rigida was eliminated through the milk at toxic doses for the kids. Management measures to prevent the poisoning are recommended.
\end{abstract}

INDEX TERMS: Toxic plants, Mascagnia rigida, Malpighiaceae, sudden death, fluoroacetic acid, semiarid, small ruminants.

${ }^{1}$ Recebido em 29 de março de 2008.

Aceito para publicação em 6 de junho de 2008.

Este trabalho faz parte da Dissertação do primeiro autor no Curso de Mestrado em Medicina Veterinária de Ruminantes e Eqüídeos, Universidade Federal de Campina Grande (UFCG), Paraíba, e foi apresentado no XIII Enapave, Belo Horizonte, em julho de 2007.

2 Pós-Graduação em Medicina Veterinária em Ruminantes e Eqüídeos,
Hospital Veterinário, CSTR, UFCG, Patos, PB 58700-000, Brasil. Email: veterinariojsv@yahoo.com.br

${ }^{3}$ Centro de Saúde e Tecnologia Rural (CSTR), UFCG, Campus de Patos, 58700-000 Patos, PB, Brasil. *Autor para correspondência: franklin.riet@pq.cnpq.br

${ }^{4}$ Bolsista de Iniciação Científica do CNPq, CSTR, UFCG, Campus de Patos, PB. 
RESUMO.- Mascagnia rigida é a planta tóxica mais importante para bovinos na região Nordeste, causando morte súbita associada ao exercício. O presente trabalho teve como objetivos descrever três surtos de intoxicação por M. rigida em ovinos e um surto em caprinos no semi-árido da Paraíba, reproduzir experimentalmente a intoxicação em ovinos e caprinos, e comprovar a passagem do princípio ativo de $M$. rigida pelo colostro destes pequenos ruminantes. Os surtos ocorreram no início do período chuvoso, quando a planta brota antes do que outras forrageiras ou após o final desse período, quando após secarem algumas forrageiras, $M$. rigida permanece verde. Na reprodução experimental da intoxicação por $M$. rigida, doses de 10 e $20 \mathrm{~g} / \mathrm{kg}$ de peso animal, com as planta proveniente de duas regiões diferentes, foram letais para três caprinos e três ovinos. Um caprino que ingeriu $20 \mathrm{~g} / \mathrm{kg}$ da planta um ovino que ingeriu $10 \mathrm{~g} / \mathrm{kg}$, se recuperaram. Dois ovinos e dois caprinos que ingeriram $5 \mathrm{~g} / \mathrm{kg}$ tiveram sinais discretos e se recuperaram. Tanto os casos experimentais quanto os espontâneos apresentaram ingurgitamento das veias jugulares, relutância em caminhar, decúbito externo abdominal, incoordenação, respiração ofegante, depressão, instabilidade e tremores musculares. A morte ocorreu após um curso clínico de alguns minutos a 27h40 min. As principais lesões foram edema pulmonar e vacuolização e necrose de células epiteliais dos túbulos renais. Para testar se o princípio ativo de $M$. rigida é eliminado pelo leite causando morte súbita nas crias foi realizado um experimento com duas cabras e cinco ovelhas que ingeriram, diariamente, $2 \mathrm{~g} / \mathrm{kg}$ de $M$. rigida, nos 15 dias anteriores ao parto. Uma ovelha que tinha gestação gemelar abortou depois de ter ingerido a planta por 10 dias. Os cordeiros das demais ovelhas mamaram normalmente o colostro sem aprestar sinais clínicos. O cabrito de uma cabra mamou o colostro e 5 minutos após morreu subitamente. A outra cabra pariu um cabrito que morreu imediatamente após o parto, sem ter ingerido colostro. Estes resultados sugerem que o princípio ativo da planta foi eliminado pelo leite em doses tóxicas. Recomendamse medidas de controle da intoxicação.

TERMOS DE INDEXAÇÃO: Plantas tóxicas, Mascagnia rigida, Malpighiaceae, morte súbita, ácido fluoroacético, semi-árido, pequenos ruminantes.

\section{INTRODUÇÃO}

Mascagnia rigida (Juss.) Griseb., conhecida popularmente pelos nomes tinguí, timbó e pela-bucho, que causa morte súbita em bovinos, é a planta tóxica mais importante da região Nordeste, nordeste de Minas Gerais e o norte do Espírito Santo (Tokarnia et al. 2000). Em condições naturais $M$. rigida causa intoxicação em bovinos (Tokarnia et al. 1994, Medeiros et al. 2002), caprinos (Oliveira et al. 1978) e ovinos (Soto-Blanco et al. 2007). Experimentalmente a intoxicação tem sido reproduzida em bovinos (Tokarnia et al. 1994), caprinos (Paraguassu 1983) ovinos (Soto-Blanco et al. 2007) e coelhos (Tokarnia et al. 1987, Medeiros et al. 2002).
Na Paraíba $M$. rigida é encontrada em quase todo o Estado (Medeiros et al. 2002). Anteriormente a planta não era descrita na Zona da Mata, mas recentemente surtos de intoxicação por $M$. rigida foram diagnosticados em bovinos nos municípios de Sapé e Jacaraú na Zona da Mata Paraibana (Vasconcelos et al. 2007). Há marcadas variações na toxicidade da planta e a ocorrência da intoxicação varia entre animais da mesma espécie, entre regiões e entre fazendas da mesma região (Riet-Correa et al. 2006). Após serem submetidos a exercícios os bovinos apresentam tremores, instabilidade e quedas com movimentos de pedalagem (Tokarnia et al. 1961, 1994). Os sinais clínicos observados nos caprinos experimentais são dispnéia, taquicardia e decúbito esternal evoluindo para decúbito lateral com movimentos de pedalagem, seguida de morte. Alguns animais menos afetados se recuperam (Paraguassu 1983). Em ovinos os sinais clínicos caracterizam-se por apatia, tremores musculares, taquicardia, dificuldades de se manter em pé, dispnéia e convulsões tônico-clônicas (Soto-Blanco et al. 2007).

Na necropsia de animais intoxicados por M. rigida não é descrita nenhuma lesão de significado (Tokarnia et al. 1991, 1994), exceto em coelhos que foi observado uma leve evidenciação do padrão lobular hepático (Tokarnia et al. 1987). No estudo microscópico a lesão de maior significado é a degeneração hidrópico-vacuolar nas células do epitélio dos túbulos contornados distais do rim (Tokarnia et al. 1987, 1994).

O princípio ativo de $M$. rigida não é bem conhecido, mas mediante estudo por cromatografia em camada delgada foi sugerido que seja o ácido monofluoracético (Cunha et al. 2007). Produtores de caprinos no semi-árido da Paraíba mencionam que cabritos nascidos de cabras pastejando em áreas com $M$. rigida morrem subitamente após a ingestão de colostro, o que sugere que o ácido monofluoracético é eliminado pelo leite causando a morte dos cabritos.

O presente trabalho teve como objetivos: descrever 4 surtos de intoxicação por M. rigida, sendo 3 em ovinos e 1 em caprinos; reproduzir experimentalmente a intoxicação em ovinos e caprinos; e comprovar a passagem do princípio ativo de $M$. rigida pelo colostro de cabras e oveIhas.

\section{MATERIAL E MÉTODOS}

Os dados epidemiológicos e clínicos dos surtos foram obtidos junto aos proprietários em visitas às propriedades onde ocorreram os mesmos. A reprodução experimental da intoxicação foi realizada no Hospital Veterinário (HV) do Centro de Saúde e Tecnologia Rural (CSTR), Campus de Patos, Universidade Federal de Campina Grande (UFCG), Patos, Paraíba. Para a reprodução experimental da intoxicação foram utilizados 18 animais, sendo 9 ovinos e 9 caprinos, divididos em 6 grupos. O Grupo 1 foi formado pelos Ovinos 1, 2 e 3 que receberam $M$. rigida coletada no município de São José do Bonfim, Paraíba, nas doses de 20, 10 e $5 \mathrm{~g} / \mathrm{kg}$ de peso animal. respectivamente. O Grupo 2 foi composto pelos Ovinos 4, 5, e 6 , que receberam M. rigida coletada no município de Cabaceiras, 
Paraíba, nas doses de 20, 10 e $5 \mathrm{~g} / \mathrm{kg}$, respectivamente. O Grupo 3, testemunha, foi formado pelos Ovinos 7, 8 e 9 . O Grupo 4 foi formado pelos Caprinos 1, 2 e 3 que receberam a $M$. rigida coletada no município de São José do Bonfim, PB, nas doses de 20, 10 e $5 \mathrm{~g} / \mathrm{kg}$, respectivamente. O Grupo 5 foi formado pelos Caprinos 4, 5 e 6, que receberam a $M$. rigida coletada no município de Cabaceiras, PB, nas doses de 20, 10 e $5 \mathrm{~g} / \mathrm{kg}$, respectivamente. O Grupo 6, formado pelos Caprinos 7, 8 e 9, foi utilizado como testemunha.

Todos os animais antes de receber a planta foram pesados e aferidos os batimentos cardíacos, movimentos respiratórios, movimentos ruminais e temperatura retal. As folhas de $M$. rigida foram administradas por via oral, colocando pequenas quantidades na boca do animal, utilizando-se folhas frescas. Quando os animais apresentavam os sinais clínicos da intoxicação por $M$. rigida era feita a observação dos mesmos até a morte ou a recuperação do animal. Os animais que morriam eram necropsiados, feita as anotações das alterações macroscópicas e coletados fragmentos de rim, coração, pulmão, fígado, baço, pré-estômagos, abomaso, intestino e o sistema nervoso central e fixados em formalina a $10 \%$ para exame histopatológico. Os órgãos das cavidades torácica e abdominal foram incluídos em parafina, cortados em secções de 4-6um e corados por hematoxilina e eosina. O sistema nervoso central, após ser fixado, foi cortado em fatias e amostras de córtex, cerebelo, núcleos da base, tálamo, colículo rostral, ponte, pedúnculos cerebrais e obex foram estudados histologicamente. Cortes selecionados do coração foram corados por PAS (Ácido Periódico de Schiff) para observar glicogênio nas fibras de Purkinje.

Para testar se o princípio ativo de $M$. rigida é eliminado pelo leite causando morte súbita nas crias foi realizado um experimento com 2 cabras e 5 ovelhas. As fêmeas foram acasaladas com machos marcados com tinta xadrez para determinar o dia da cobertura. Trinta dias após a prenhez foi confirmada por ultra-sonografia. Tanto para as cabras como para as ovelhas a planta foi administrada, diariamente, $2 \mathrm{~g} / \mathrm{kg}$, por 15 dias até a data do parto. A planta administrada era conservada na geladeira a $5^{\circ} \mathrm{C}$ por até 15 dias.

\section{RESULTADOS}

\section{Surtos espontâneos}

O surto da intoxicação por Mascagnia rigida em caprinos ocorreu numa fazenda no município de Cabaceiras, PB. Os caprinos pastavam em uma área que continha grande quantidade de $M$. rigida. A intoxicação ocorria, desde anos anteriores, com mais freqüência durante a época seca, nos meses de julho, agosto e setembro. A quantidade de animais que morriam variava de 12 a 15 caprinos por ano de um rebanho de aproximadamente 300 animais. Os caprinos acometidos eram adultos. Segundo o proprietário os sinais clínicos só eram observados quando os animais eram forçados a se exercitarem e consistiam em relutância em caminhar e queda, permanecendo em decúbito lateral, com movimentos de pedalagem, taquipnéia, berros e morte em 3 a 5 minutos após o início dos sinais. Alguns animais que apresentavam relutância em caminhar e eram deixados no campo, quietos, sem serem forçados a se movimentarem, recuperavam-se de 24 a 48 horas após o início dos sinais.
Os surtos da intoxicação por $M$. rigida em ovinos ocorreram nos municípios de São José do Bonfim e Cacimbas, PB. Os dois primeiros surtos ocorreram na localidade de Carnaúba dos Pires, no município de São José do Bonfim, em fevereiro de 2006, logo após as primeiras chuvas. No primeiro surto de um rebanho de 30 ovinos, 2 animais foram encontrados mortos e 4 apresentaram sinais clínicos. Destes, 2 morreram e 2 se recuperaram. Os sinais clínicos descritos pelo proprietário eram de tremores musculares, relutância em caminhar e queda. No segundo surto, de um rebanho de 12 animais, 9 adoeceram e destes, 2 morreram e 7 se recuperaram. Os sinais clínicos apresentados pelos ovinos intoxicados foram semeIhantes aos apresentados pelos ovinos do primeiro surto.

O terceiro surto ocorreu no município de Cacimbas, PB em novembro de 2006, no qual, de 40 ovinos, 2 morreram após serem trazidos para o curral. O proprietário informou que em 2004, morreram 5 ovinos de aproximadamente 40, 50 caprinos de um rebanho de 80 e 3 bovinos de um rebanho de 20. Todos os animais morreram após serem exercitados, apresentando os mesmos sinais clínicos observados nos ovinos. Nesta fazenda, os animais se intoxicaram na época de estiagem, quando não havia mais pasto e M. rigida (Fig.1) continuava verde. Foi

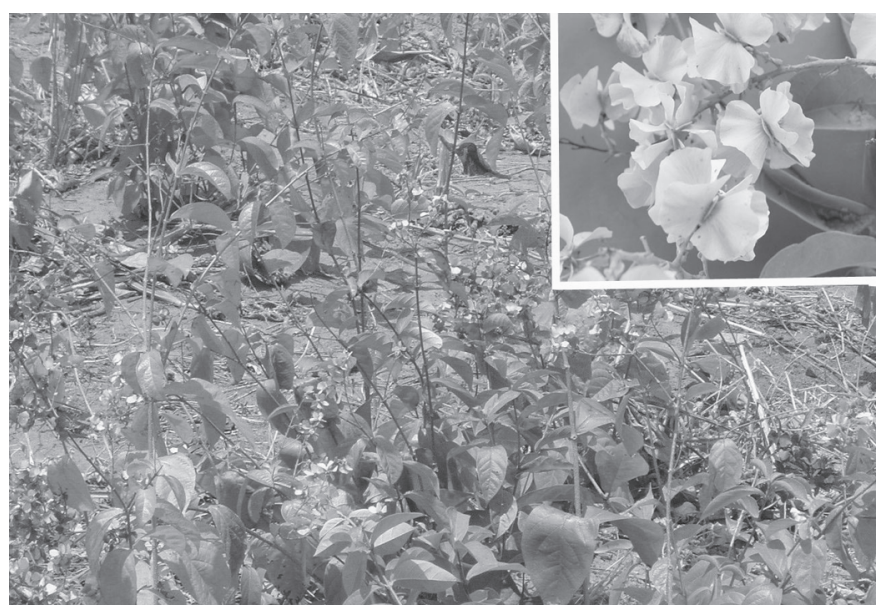

Fig.1. Mascagnia rigida em fase de frutificação e floração. Inserido: frutos e folhas da planta. Município de Cacimbas, PB.

necropsiado um ovino. Os pulmões estavam parcialmente colapsados com edema e havia presença de folha de $M$. rigida no rúmen. Na histologia foi observado edema pulmonar e degeneração hidrópico-vacuolar e necrose das células epiteliais dos túbulos renais.

\section{Casos experimentais}

O início dos sinais clínicos e a evolução da intoxicação experimental por $M$. rigida em ovinos estão descritos nos Quadros 1 e 2, e nos caprinos nos Quadros 3 e 4.

Os Ovinos 1, 2, e 4 apresentaram ingurgitamento das veias jugulares (Fig.2), relutância em caminhar, decúbito externo abdominal, incoordenação, respiração ofegante, 
Quadro 1. Intoxicação experimental por Mascagnia rigida em ovinos com planta coletada no município de São José do Bonfim, PB

\begin{tabular}{cccccc}
\hline \multirow{2}{*}{$\begin{array}{c}\text { Ovino } \\
\text { no }\end{array}$} & $\begin{array}{c}\text { Peso } \\
(\mathrm{kg})\end{array}$ & $\begin{array}{c}\text { Dose } \\
(\mathrm{g} / \mathrm{kg})\end{array}$ & \multicolumn{2}{c}{ Sinais clínicos } & Evolução \\
\cline { 4 - 5 } & & Início $^{\text {a }}$ & Duração & \\
\hline 1 & 35 & 20 & 02h25min & 07h49min & Morreu \\
2 & 34 & 10 & 02h35min & 20h05min & Morreu \\
3 & 35 & 5 & 05h40min & 13h20min & Recuperou-se \\
\hline
\end{tabular}

a Início dos sinais clínicos após administração da planta.

Quadro 2. Intoxicação experimental por Mascagnia rigida em ovinos com planta coletada no município de Cabaceiras, PB

\begin{tabular}{|c|c|c|c|c|c|}
\hline \multirow{2}{*}{$\begin{array}{c}\text { Ovino } \\
\text { no }\end{array}$} & \multirow{2}{*}{$\begin{array}{c}\text { Peso } \\
(\mathrm{kg})\end{array}$} & \multirow{2}{*}{$\begin{array}{l}\text { Dose } \\
(\mathrm{g} / \mathrm{kg})\end{array}$} & \multicolumn{2}{|c|}{ Sinais clínicos } & \multirow[t]{2}{*}{ Evolução } \\
\hline & & & Início ${ }^{a}$ & Duração & \\
\hline 4 & 18 & 20 & 03h20r & 20 & \\
\hline 5 & 17 & 10 & 06h35min & $18 \mathrm{~h} 20 \mathrm{~min}$ & Recuperou-se \\
\hline 6 & 16 & 5 & $12 \mathrm{~h} 25 \mathrm{~min}$ & $11 \mathrm{~h} 15 \mathrm{~min}$ & Recuperou-se \\
\hline
\end{tabular}

a Início dos sinais clínicos após administração da planta.

Quadro 3. Intoxicação experimental por Mascagnia rigida em caprinos. Planta coletada no município de São José do Bonfim, PB

\begin{tabular}{|c|c|c|c|c|c|}
\hline \multirow{2}{*}{$\begin{array}{c}\text { Coelho } \\
\text { no }\end{array}$} & \multirow{2}{*}{$\begin{array}{c}\text { Peso } \\
(\mathrm{kg})\end{array}$} & \multirow{2}{*}{$\begin{array}{l}\text { Dose } \\
(\mathrm{g} / \mathrm{kg})\end{array}$} & \multicolumn{2}{|c|}{ Sinais clínicos } & \multirow[t]{2}{*}{ Evolução } \\
\hline & & & Início ${ }^{a}$ & Duração & \\
\hline 1 & 20,0 & 20 & $01 \mathrm{~h} 0 \mathrm{n}$ & 01h54min & \\
\hline 2 & 11,6 & 10 & 05h00min & $24 \mathrm{~h} 30 \mathrm{~min}$ & Morreu \\
\hline 3 & 15,0 & 5 & 04h35min & $13 \mathrm{~h} 55 \mathrm{~min}$ & Recuperou-se \\
\hline
\end{tabular}

a Início dos sinais clínicos após administração da planta.

Quadro 4. Intoxicação experimental por Mascagnia rigida em caprinos. Planta coletada no município de Cabaceiras, PB

\begin{tabular}{|c|c|c|c|c|c|}
\hline \multirow{2}{*}{$\begin{array}{c}\text { Coelho } \\
\text { no }\end{array}$} & \multirow{2}{*}{$\begin{array}{c}\text { Peso } \\
(\mathrm{kg})\end{array}$} & \multirow{2}{*}{$\begin{array}{l}\text { Dose } \\
\text { (g/kg) }\end{array}$} & \multicolumn{2}{|c|}{ Sinais clínicos } & \multirow[t]{2}{*}{ Evolução } \\
\hline & & & Início ${ }^{a}$ & Duração & \\
\hline 4 & 17, & 20 & 0 & & \\
\hline 5 & 15,3 & 10 & 02h00min & 27h40min & Morreu \\
\hline 6 & 20,0 & 5 & $10 \mathrm{~h} 25 \mathrm{~min}$ & 09h00min & Recuperou-se \\
\hline
\end{tabular}

a Início dos sinais clínicos após administração da planta.

depressão, instabilidade, tremores musculares, tremores da cabeça, discreto tremores das orelhas e, no Ovino 2, tremores dos lábios e pálpebras, bruxismo e crises convulsivas. Os Ovinos 3 e 6 apresentaram somente uma leve taquicardia. Na necropsia dos Ovinos 1, 2 e 4 foi observado hidropericárdio e petéquias nas superfícies pleural e subepicárdica. No Ovino 2 o fígado apresentava evidenciação discreta do padrão lobular. Nos três ovinos os pulmões estavam parcialmente colapsados edemaciados e com líquido espumoso na traquéia. No Ovino 4 a vesícula biliar encontrava-se repleta. Em todos os ovinos foram encontradas folhas de $M$. rigida no rúmen.

Os Caprinos 1, 2 e 5 apresentaram ingurgitamento das veias jugulares, taquicardia, taquipnéia, respiração ofegante, relutância em caminhar e tremores musculares. Nos

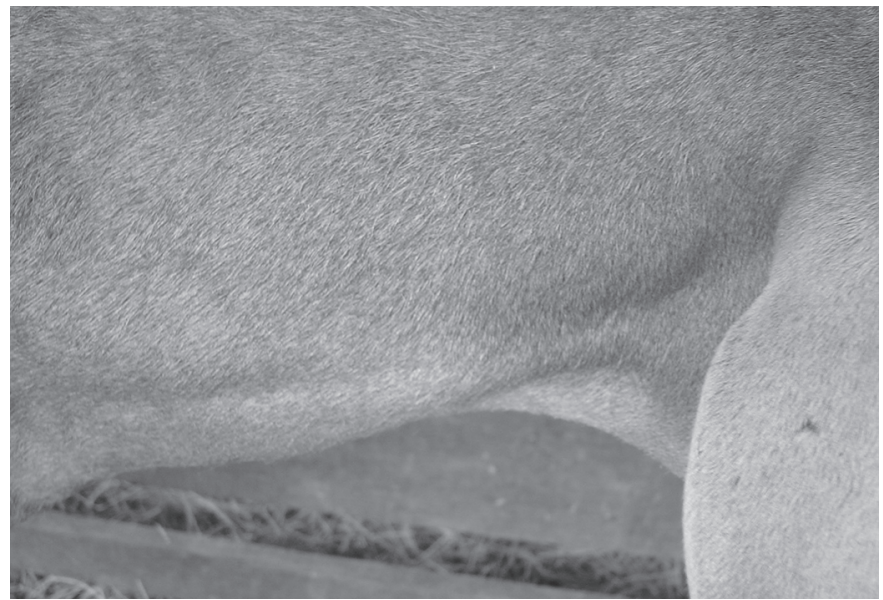

Fig.2. A veia jugular ingurgitada, no Ovino 1.

Caprinos 2 e 5, que tiveram uma evolução mais lenta foram observados quedas repetidas com movimentos de pedalagem. O Caprino 1 apresentou alguns berros e ingurgitamento das veias jugulares, caindo e morrendo em aproximadamente 4 minutos. Os Caprinos 3 e 6 apresentaram somente leve taquicardia. Os achados macroscópicos encontrados consistiam em evidenciação discreta do padrão lobular, vesícula biliar repleta, pulmões úmidos edemaciados e brilhantes e presença de folhas de $M$. rigida no conteúdo ruminal.

Microscopicamente foi observado, em todos os ovinos e caprinos, edema pulmonar moderado e degeneração hidrópico-vacuolar e necrose das células do epitélio de alguns túbulos renais, principalmente na região corticomedular. No Caprino 2 a degeneração hidrópico-vacuolar e necrose das células do epitélio era mais acentuada (Fig.3). Essa lesão renal se caracterizava por núcleo picnótico e citoplasma difusamente vacuolizado. Nos Caprinos 1,2 e 5 foi observado dilatação e vacuolização difusa das fibras de Purkinje do coração (Fig.4).

No experimento realizado para determinar se o princí-

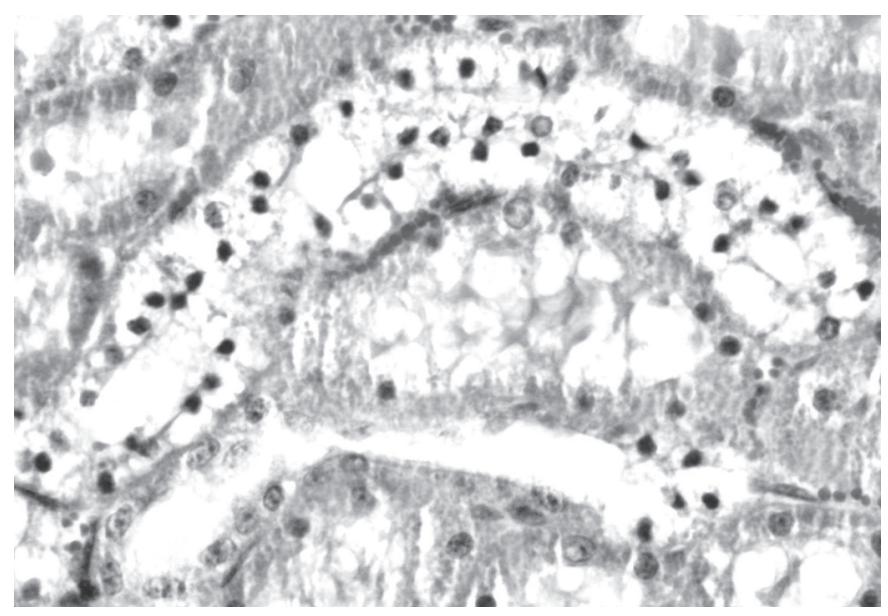

Fig.3. Rim apresentando degeneração hidrópico-vacuolar e necrose das células epiteliais dos túbulos (Caprino 2). HE, obj.40x. 


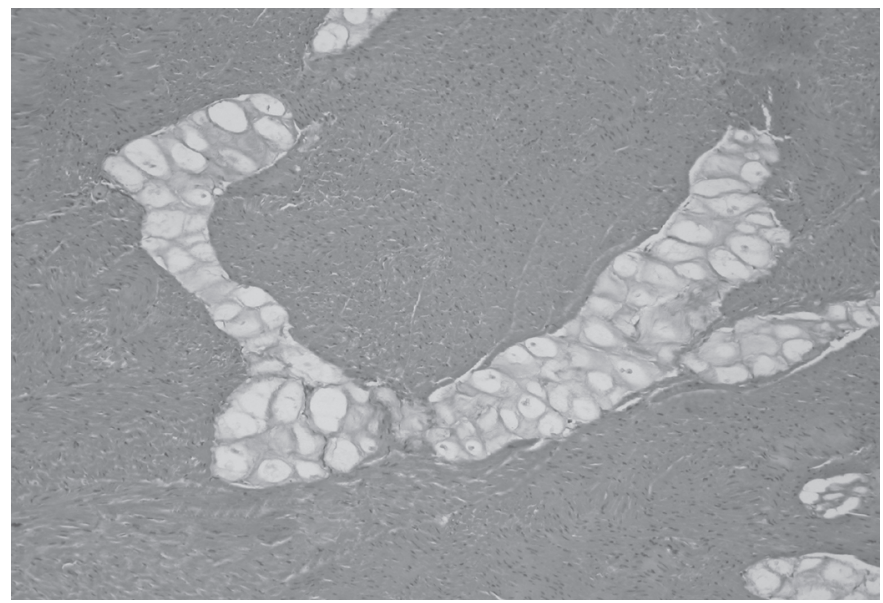

Fig.4. Coração apresentando vacuolização e dilatação das fibras de Purkinje (Caprino 2). HE, obj.10x.

pio ativo de $M$. rigida é eliminado pelo leite, uma ovelha que tinha gestação gemelar abortou depois de ter ingerido a planta por 10 dias. Os cordeiros (únicos) das demais ovelhas mamaram normalmente o colostro sem aprestar sinais clínicos. O cabrito de uma cabra mamou o colostro e 5 minutos após começou a se debater, caindo e morrendo logo em seguida. Na necropsia não foi observada nenhuma lesão macroscópica. No estudo histológico não foi observada lesão digna de nota. A outra cabra pariu um cabrito que morreu imediatamente após o parto, sem ter ingerido colostro.

\section{DISCUSSÃO}

Os resultados deste trabalho e de trabalhos anteriores (Oliveira et al. 1978, Soto-Blanco et al. 2007) sugerem que $M$. rigida, que tinha sido descrita inicialmente como uma planta tóxica importante para bovinos no semi-árido, é também uma planta tóxica importante para caprinos e ovinos nesta região.

Neste trabalho ficou evidente que numa mesma região a intoxicação por M. rigida ocorre em duas situações epidemiológicas diferentes. Em ovinos, no município de São José do Bonfim, a intoxicação ocorreu no início da estação chuvosa, quando $M$. rigida começa a brotar e ainda há pouca disponibilidade de forragem. No caso do surto em ovinos que ocorreu no município de Cacimbas e em caprinos no município de Cabaceiras os animais foram acometidos durante a seca, quando as folhas da $M$. rigida ainda permanecem verdes e as outras forragens já estão secas.

A condição epidemiológica para que ocorra a intoxicação por M. rigida no semi-árido em ovinos e caprinos, em épocas diferentes, poderia estar ligada ao clima e ao relevo. Os municípios de Cacimbas e Cabaceiras ficam a alturas de $645 \mathrm{~m}$ e $388 \mathrm{~m}$, respectivamente, com uma temperatura média de $24^{\circ} \mathrm{C}$ (Prefeituras Municipais de Cacimbas e Cabaceiras 2008). Nestas condições M. rigida permanece verde por alguns meses, mesmo após o final do período das chuvas, causando intoxicação durante a época seca. Por outro lado, o município de São José do Bonfim, que fica numa depressão a $278 \mathrm{~m}$ de altitude, com uma temperatura média anual de $28^{\circ} \mathrm{C}$ (Prefeitura Municipal de São José do Bonfim 2008), apresenta um clima bem mais quente, conseqüentemente a vegetação, incluindo $M$. rigida, seca rapidamente após o início da seca. Nestas condições a ingestão da planta somente ocorre após o início das chuvas.

No Rio Grande do Norte todos os 4 surtos descritos em ovinos ocorreram no início das chuvas, em rebanhos que tinham sido recentemente introduzidos nas fazendas. Sendo que em um surto os animais recentemente introduzidos morreram e os que permaneciam há pelo menos um ano na fazenda não adoeceram (Soto-Blanco et al. 2007). Essa situação, que não foi observada nos surtos descritos neste trabalho, sugere que há resistência, adquirida ou genética, em animais criados em áreas onde ocorre $M$. rigida.

Nos experimentos descritos neste trabalho não foram observadas variações significantes na toxicidade das amostras de $M$. rigida coletada em duas regiões diferentes. No entanto, outros trabalhos relatam variações importantes na toxicidade da planta (Tokarnia et al. 1961, 1994, Medeiros et al. 2002). Essas prováveis variações devem ser também consideradas na epidemiologia da intoxicação.

Os sinais clínicos apresentados pelos caprinos são semelhantes aos sinais clínicos descritos em bovinos (Tokarnia et al. 1961, 1994). Macroscopicamente a única lesão significante observada foi o edema pulmonar. Esta lesão, associada à insuficiência cardíaca, não foi reportada em trabalhos anteriores em bovinos (Tokarnia et al. 1961, 1994), caprinos (Paragussu 1983) e ovinos (SotoBlanco et al. 2007). Semelhante ao observado em bovinos (Tokarnia et al. 1961, 1994) a lesão histológica mais importante é a vacuolização e necrose de células epiteliais dos túbulos renais. Lesão semelhante à observada no rim foi observada nas células de Purkinje do coração de dois caprinos; apesar de que essa lesão não é observada em caprinos e ovinos sadios, não temos certeza de que se trate de uma lesão ou de artefato histológico.

Considerando os fatores epidemiológicos mencionados anteriormente algumas medidas de profilaxia poderiam ser recomendadas. Como a intoxicação é, aparentemente, sazonal, é importante ter cuidados especiais com os caprinos e ovinos no início das chuvas e após o período das chuvas, se possível tirando os animais das áreas de risco durante esses períodos. No início das chuvas poderiam ser retirados até que haja a brotação de outras plantas forrageira diminuindo os riscos de ingestão de $M$. rigida. Considerando que muitos animais com sinais clínicos se recuperam se forem deixados sem movimentar é importante, ao igual do que ocorre em bovinos, ter cuidados para remover os animais das áreas onde estejam ocorrendo mortes. Neste caso a medida recomendada para bovinos é a de retirar os animais lentamente, para 
uma área próxima onde não ocorra a planta e esperar de 8 a 14 dias para movimentá-los novamente (Tokarnia et al. 2000).

Os resultados do experimento com administração de $M$. rigida a ovelhas e cabras prenhes sugerem que em ovelhas não há passagem do princípio ativo de $M$. rigida pelo colostro em doses tóxicas para os cordeiros. No entanto, em caprinos, a morte súbita de cabrito após a ingestão de colostro sugere ocorre a passagem do princípio ativo pelo colostro em quantidade suficiente para causar a morte do cabrito. Novos experimentos deverão ser realizados para comprovar esta hipótese.

Agradecimentos.- Este trabalho foi financiado pelo Programa de Apoio a Núcleos de Excelência (Pronex, Proc,001/04), CNPq, FAPESQ, MCT, e pelo programa Institutos do Milênio (Proc.420012/2005-2), CNPq. O primeiro autor agradece ao CNPq pela concessão da bolsa de mestrado.

\section{REFERÊNCIAS}

Cunha L.C., Gorniak S.L., Haraguchi M., Riet-Correa F., Xavier F.G. \& Florio J.C. 2006. Palicourea marcgravii e Mascagnia rigida: um estudo por cromatografia em camada delgada (CCD). II Simpósio de PósGraduação e XV Semana Científica Prof. Dr. Benjamin Eurico Malucelli, São Paulo, em CD-ROM. (Resumo)

Medeiros R.M.T., Geraldo Neto S.A., Barbosa R.C., Lima E.F. \& RietCorrea F. 2002. Sudden death caused by Mascagnia rigida in cattle in Paraíba, Northeastern Brazil. Vet. Human Toxicol. 44(5):286-288.

Oliveira A.C., Oliveira G.C., Paraguassu A.A. \& Freire L.M.G.M. 1978. Intoxicação por um "tíngui" (Mascagnia rigida Griseb.) em caprinos na Bahia. XVI Congr. Bras. Med. Vet., Salvador, Bahia, p.172. (Resumo)

Paraguassu A.A. 1983. Intoxicação Experimental por Mascagnia rigida Grisebach (Malpighiaceae) em caprinos no Nordeste do Brasil. Dis- sertação de Mestrado, Univ. Fed. Rural do Rio de Janeiro, Itaguaí, RJ. 65p.

Passos D.A. 1983. Intoxicação experimental em caprinos (Capra hircus) por Palicourea aeneofusca (M.Arg.) Standl. (Rubiaceae). Dissertação de Mestrado, Univ. Fed. Rural de Pernambuco, Recife, PE. 40p.

Prefeitura Municipal de Cabaceiras, PB. http://www.cabaceiras. paraiba.com.br/. Acessado em 15.2.2008.

Prefeitura Municipal de Cacimbas, PB. http://www.cacimbas. paraiba.com.br/. Acessado em 15.2.2008.

Prefeitura Municipal de São José do Bonfim, PB. http:// www.saojosedobonfim.paraiba.com.br/. Acessado em 15.2.2008.

Riet-Correa F., Medeiros R.M.T., Dantas A.F.M. 2006. Plantas Tóxicas da Paraíba. Centro de Saúde e de Tecnologia Rural/SEBRAE/PB, Patos, p.1-58.

Soto-Blanco B., Pacífico S.I., Lira R.A, Barbosa R.R. \& Batista J.S. 2007. Intoxicação natural pelas folhas de Mascagnia rigida (Malpighiaceae) em ovinos. VII Congresso Brasileiro de Buiatria, em CD-ROM. (Resumo)

Tokarnia C.H., Canella C. \& Döbereiner J. 1961. Intoxicação por um "tinguí" (Mascagnia rigida Griseb.) em bovinos no Nordeste do Brasil. Arqs Inst. Biol. Anim., Rio de J., 4:203-215.

Tokarnia C.H., Döbereiner J. \& Canella C. 1987. Intoxicação experimental por Mascagnia rigida (Malpighiaceae) em coelhos. Pesq. Vet. Bras. 7(1):11-16

Tokarnia C.H., Döbereiner J. \& Peixoto P.V. 1994. Aspectos clínicopatológicos complementares da intoxicação por algumas plantas tóxicas brasileiras. Pesq. Vet. Bras. 14(4):111-121.

Tokarnia C.H., Döbereiner J. \& Peixoto P.V. 2000. Plantas Tóxicas do Brasil. Editora Helianthus, Rio de Janeiro, p.26-27.

Vasconcelos J.S., Riet-Correa F., Dantas A.F.M., Medeiros R.M.T. \& Dantas A.J.A. 2008. Mortes súbitas causadas por Palicourea aeneofusca e Mascagnia rigida na Zona da Mata Paraibana. Pesq. Vet. Bras. 28(10):457-460 